\title{
Conceptualizations, Principles, Guidelines, and Models and Teaching Practice Present in Teacher Training
}

\author{
Claudio Pinto Nunes \\ Universidade Estadual do Sudoeste da Bahia, Bahia, Brazil
}

\begin{abstract}
This article aims to present and promote a reflection on the conceptualizations, principles, guidelines, and models that are expressed in teacher training and in teachers' pedagogical practices, both in the professional workplaces of experienced teachers and during the undergraduate courses. It is an exploratory analytical and reflective study focused on teacher training and pedagogical practice. The text also points out the need that teacher training be theoretically and epistemologically anchored so that teachers will be able to develop new strategies for an effective initial and continuing training in order to promote the passing of a reiterative practice to a creative pedagogical one, which may be able even to establish new conceptualizations, principles, guidelines, and reference models.
\end{abstract}

Keywords: conceptualization, principles, guidelines, models, teacher training, pedagogical practice

\section{Introduction}

To understand the process of initial teacher training is pertinent to turn the attention to the contributions by some authors who were engaged in discussing elements that are basic to elucidate the bases that support most of the insights about training teachers around the world.

From that perspective, this article aims at discussing the conceptual guidelines on teacher training as developed by Feiman-Neimser (1990), the training models elaborated by Altet (1994), and the training principles and the conceptualization developed by Marcelo García (1995).

Worthy to be mentioned, even briefly, is the fact that similar work had been carried by Zeichner (1983), Mizukami (1986), Saviani (1983; 1995), Simões (1987), Pérez-Gómez (1992), among others. Thus, the present article is the result of a study of exploratory and bibliographical nature.

\section{Contributions by Feiman-Neimser (1990): Conceptual Guidelines for Teacher Training}

Attention is initially called, too, to the conceptual guidelines for teacher training developed by Feiman-Neimser (1990). It is noteworthy that from her perspective, Feiman-Neimser (1990) referred to teacher training by using the term "teacher education".

When it comes to conceptual guidelines or approaches or paradigms for teacher training, it is worth making it clear that, in accordance with Feiman-Neimser (1990), one single guideline is not wide enough to grasp all the complexity of teacher training. Then, in that sense, one presents and discusses the five conceptual

Claudio Pinto Nunes, Ed.D., leader of the Study Group on Didactics, Training, and Teaching Work; professor, Universidade Estadual do Sudoeste da Bahia. 
guidelines developed by Feiman-Neimser (1990) about teacher education. The order that the guidelines, which are listed here, follows the same order they are arranged in the text by Feiman-Neimser (1990).

The first conceptual orientation reported by Feiman-Neimser (1990) is the academic one, which comprises the act of teaching as a synonym for knowledge transmission. According to this guidance, the teacher is seen as an expert in certain subjects or contents. Prospective teachers are trained according to this guidance by learning the contents developed by science and knowledge transmission is their role.

The second conceptual orientation to which Feiman-Neimser (1990) referred is the personal one. According to this guidance, teaching is centered on the personal development of the subject under training seeking his/her self-realization. Thus, it is understood that the individual should be encouraged and guided - not shaped - according to the meanings that the training process has for him/her. There is therefore great valorization of the subjectivities of the individuals under training. Prospective teachers are instructed in their training processes to develop their personal potentialities.

The third conceptual guidance referred to by Feiman-Neimser (1990) is the critical/social one. According to this guidance, the teacher should have a progressist social view and be able to elaborate a radical criticism of the education system. This progressist social view and this capacity to criticize radically the education system are developed, according to this guidance, from a participative dynamics by the educator. Thus, the teacher is seen as an active and critical participant educator in the social life and in the community in which the school is inserted, in order to contribute to the formation of a more just and democratic society. Prospective teachers are instructed in their training processes to develop critical sense in relation to the social issues of the scope of coverage of their professional activities.

The fourth conceptual orientation according to Feiman-Neimser (1990) is the technology. According to this conceptual orientation, training of prospective teachers must excel the principles or rules to be taught and used by the teacher in making decisions regarding effective teaching. In this context, prospective teachers are instructed in their training processes to develop their technical potentialities in relation to the act of teaching. Teaching is understood as a purely technical activity.

The fifth and final conceptual guidance developed by Feiman-Neimser (1990) is the practice. This conceptual orientation considers as important in teacher training that prospective teachers develop observation and imitation activities by experienced teachers, but she adds the importance of critical sensibility. Thus, not only the practical or uneventful capability is taken as relevant, but also the ability, flexibility, and invention. These abilities, according to this author, can only be attained through practice or through the dialogue with practice. But practice here is understood as the main source of knowledge. Thus, prospective teachers are instructed in their training processes to develop the pedagogical practice establishing a critical dialogue with the existing practices and theories.

Although she listed these conceptual guidelines for teacher education, Feiman-Neimser (1990) stated that each of the guidelines referred to by her has very significant specificities for teacher training, but she pointed out that none of them individually meets all the requirements to guide the development of a training program. This text takes the position of agreement with Feiman-Neimser (1990) and highlights the need that initial training courses for teachers seek to promote the training processes of prospective teachers in order to cover the multiplicity of perspectives, approaches, paradigms, and guidance. Prospective teachers must take from the initial training the necessary bases so that they can develop a grounded pedagogical practice in understanding 
the need to establish a constant dialogue between the developed practice and theoretical discussions of educational sciences.

\section{Altet's (1994; 2000) Contributions: Teacher Training Models}

Continuing this discussion, the attention turns to referring to the models of teaching and training, highlighting the relationship between theory and practice in the context of these models. To do so, these models turn and focus on the steps and professionalization as listed by Altet (1994).

Thus, when dealing with the initial training of teachers, it is necessary to bear in mind the understanding that one has of practice and theory underlying this practice. In this sense, understanding the practice requires understanding the theory as well. At the same time, understanding the theory also implies understanding the manifestation of this theory in the pedagogical practices by prospective teachers in the situations of supervised curricular stage. Thus, one brings to this discussion Altet's (1994) contribution to understand the idea of practice and the relationship between theory and practice in the context of teacher training.

Therefore, Altet (1994) initially correlated and distinguished the understanding that one has of profession with the understanding of métier. In this sense, she highlighted that the basic difference between profession and métier lies precisely in the nature and meaning of training for the exercise of each of these activities. She stated that training — or the preparation - for the exercise of a certain métier occurs in a technical way by the implicit transfer of know-how through imitation and experience. On the other hand, professional training, according to Altet (1994), occurs through an explicit and rational process, besides being a formation that takes place with a view to building a professional identity.

In this context, Altet (1994) put in parallel the evolution of educational models and training models analyzed by her within the initial teacher training, while considering, from an articulation of the theory and practice, four stages of professionalization. Thus, she stands out as a first model of teaching and training the intellectualist education of antiquity, which considered the teacher as a master, a wizard who was wise by nature and, therefore, did not need to go through any training. The understanding that one had at that time was the one that needed no theories to train the teacher, because his/her charisma was enough to be a teacher. In this conception of a model of "preparing the teaching being", there is no professionalization, because the individual who teaches, in this view, is not a professional.

From Altet's (1994) perspective, the second model of teaching and training comes with the advent of the normal schools, whose training took place in the métier by imitative learning. The initial teacher training model, thus, was supported in the practice of an experienced teacher who transmitted his/her savoir-faire, that is, his/her "tricks" and teaching methods, in short, his/her modus operandi of giving classes. This experienced teacher was, then, understood, as a model to be imitated by the students. The teacher's initial training was given by imitation, observation, and imitative experimentation of this practice of this experienced teacher.

The third teaching model and training mentioned by Altet (1994) is supported by the scientific contributions of the humanities, which, in turn, were based on rationalization of the practice understood as the theory application. In this sense, the training took place by theorists.

Finally, the fourth model of teaching and training, according to Altet (1994), replaces the model of practice understood as the application of the theory by the model of the dialectical relationship that occurs through the reflection in action, reflection understood as an analysis process of the very practices, in order to identify problems and devise strategies for their solution. 
Later, Altet (2000), focusing on just training and not including teaching, presented an even more enlightening sort of classification of her understanding on teacher training models, although she did not omit her previous classification (Altet, 1994). In this sense, she listed five training models, which are presented below. The order in which the guidelines are listed here follows the same order that they are arranged in the text by Altet (2000).

The first training model developed by that other work by Altet (2000) refers to the handmade model. From the perspective of the handmade model, it just takes that the student on the last degree observes and imitates the practical savoir-faire of an experienced teacher in order to become a good teacher.

The second training model according to Altet (2000) is the academic one. According to this model, the teacher understood as a master, a wizard whose mainly initial training is based on the acquisition of knowledge and reproduction of models and behaviors.

The third model of training according to Altet (2000) is the technological one. According to the technological model, the theoretical component of the training is understood as a means to achieve the skills necessary to be a good teacher. Emphasis is placed on acquiring skills and domain capabilities, understood as observable behaviors.

The fourth model of training according Altet (2000) is the personalist one. From the perspective of the personalistic model, for good professional performance, it is necessary that the teacher has training focused on personal development. That is, a kind of training that focuses on the development of the prospective teacher as a person. In this sense, the teacher training process, notably the initial training, should seek psychological maturity of the subject in order to facilitate understanding each other.

The fifth training model according to Altet (2000) is the model of the social and critical actor. For the model of the critical and social actor, teacher training should focus in a critical and reflexive way on the social reality that prospective teachers will face; it is understood that the teacher has an important role as an agent of social transformation.

Safe-guarded each one's perspectives, the two authors (Feiman-Neimser, 1990; Altet, 2000) bring, therefore, discussions that complete each one. However, it may be noted that many other studies (Zeichner, 1983; Mizukami, 1986; Simões, 1987; Saviani, 1983; 1995; Pérez-Gómez, 1992; Pessoa, 2001) that present other perspectives similar to the authors' here submitted.

\section{Contributions by Marcelo García (1995): Conceptualization and Principles of Teacher Training}

Considering that this study focuses on the relationship between theory and practice in the context of initial teacher training, now, a concept is presented for the term "training". In this sense, one resorts to Marcelo García (1995). This author stated that in countries like France and Italy, teacher training is referred to by the term "preparation" or even "teacher training". This author also highlighted that in countries like the United States and England, teacher training is designated by the term "teacher education" or even "teacher training". Here, in this study, it is assumed a position, in accordance with Marcelo Garcia, and it uses the term "teacher training". It is understood the scope of the term "teacher education". However, in this article, the option is the term "teacher training", as already mentioned, especially to the fact that it is recurrent in discussions of different authors (mainly Brazilian authors) who use in their studies and research the term "teacher training". Thus, the discussions follow by reference to the following question: What is, in fact, training, and more specifically, 
teacher training?

The training here is taken from the perspective of Marcelo García (1995), that understands it from its social function of transmitting and for its construction of knowledge/expertise, of savoir-faire and know-being. In this sense, one can understand the term "training" as a process of development and structuring of a person, which go through both its psychological, sociological, philosophical, and their learning opportunities.

In order to understand the term, there is a need to consider the perspective in which this term is taken, given the place occupied by the subjects. Thus, one can refer to training that is organized in view of the subjects to which the preparation processes are given. Also, one can refer to the training that the very knowing subject develops from their own initiatives.

The term "formation", as a process, is different from training and preparation. Teacher training or preparation or even teacher education refers to processes in which there is someone who teaches and someone who learns technically. Formation, in this sense, becomes a broader term by referring to formative processes starting from the possibility of reflection by both those who teach and those who learn.

However, you need to delve a little more about the concept of training, when it is on the training of teachers in order to better understand its consequences within what goes on in educational institutions and schools in the field of pedagogical practices, result of that training. Therefore, one refers once again to Marcelo García (1995). This author stated that occurring the development of teacher education is necessary to specify and understand the principles underlying its process. Thus, Marcelo García (1995) presented eight principles underlying the training of teachers, to which a brief reference as follows.

The first principle is to conceive teacher training as an ongoing process. This means the close relationship between initial training and continuing education; the latter understood as a sequence or the unfolding of the first in a cumulative and interactive perspective.

The second principle of teacher training according to Marcelo García (1995) is the need to integrate the training of teachers to processes of change, innovation, and curriculum development.

The third principle concerns the need to connect or relate teacher training processes with the organizational development of the school and the pedagogical practice. If one thinks that school is constantly changing, the initial training of teachers (and, likewise, continuing training) should reflect, of course, these change processes.

The fourth principle concerns the need for articulation and integration between training regarding the proper academic and disciplines content and the pedagogical training of teachers. From the training conceptualization as developed by Marcelo García (1995), one can infer that this articulation between academic contents and pedagogical training be one of the points that most clearly demarcates the distinction between formation and training or preparation to which he refers. The notion of training related to the teacher's activity, in this perspective, brings together the idea of learning the academic and disciplinary contents and learn, too, the teaching methodologies.

The fifth principle calls the attention to the need to promote an integration between theory and practice in teacher training. This implies that the discussions of a more theoretical nature of educational sciences should be an epistemological reflection on the practice.

The sixth principle highlighted by Marcelo García (1995) refers to the need to seek the isomorphism between "received" training by the teacher and the type of education that is expected of him/her when he/she later develops in the profession, or even in the experiences on supervised curriculum practicums. 
The seventh principle emphasizes the need to know the personal, cognitive, contextual, relational features, among others, of every student, the prospective teacher, or the teacher himself/herself (when it comes to continuing education) in order to develop their skills and potentialities. In other words, one wants to point out that the teacher training classes are composed of subjects marked by their specificities and idiosyncrasies, which requires attention for heterogeneity of each class from the teacher trainer.

Finally, the eighth principle listed by Marcelo García (1995) highlights the need for teacher trainer of teachers organize the training process in order to provide a reflection on the trainees' part, both with regard to their own teaching practice and with respects to their beliefs or theoretical aggregations.

This article agrees, once more, with Marcelo García (1995) on the need to understand all these principles underlying their training process, understood as a fundamental requirement for the occurrence of the development of teacher training. It is understood that other principles may be added to those from the continuing debate in other studies.

Certainly, the disputes underlying the initial training of teachers are not limited by observing these principles, but the continuous and constant observation of such principles should be a very important point if one aims at an education with more qualified teachers for the current demands. So, here, it is argued that the degree courses need to set up working teams with the purpose of analyzing and continuously assessing their curricula, in view of the quality of training that develops with their students in the first instance, and close to society, more broadly.

Once, one understands the conceptual guidance on teacher training developed by Feiman-Neimser (1990), the training models developed by Altet (1994), and the training and conceptualization as developed by Marcelo García (1995), one needs to bring to the discussion understandings that one has about pedagogical practice.

\section{Concepts of Practice and Teaching Practice}

Although it is a general rule in the context of schools and teacher training courses that the notion of practice and of teaching practice be related to the idea represented by the action or by the everyday making in education or that this practice be the same as the act of teaching. It still seems relevant to analyze the concept of practice present in the academic research by some authors that stand out in the field of education.

Pimenta (2005), while devising a concept for the practical term, following the course of the history of teacher training, keeps on the exercise of thinking practice in some moments in the history of Brazilian education.

In this sense, the author presented as the first understanding of the concept of practice revealed by training courses in the late 1960s, the practice understood as gaining experience. But she pointed out that teacher training courses provided prospective teachers with just a notion of practice, taking it as systematic concern in the course curriculum.

So, thinking the concept of practice until the late 1960s implied from such questions as: What was teacher training? What is the stage of development of this profession? What is the economic, political, social, and cultural context? What practice was expected by teachers and what is the purpose of this practice? Once, thinking on these issues, it was up to the students of teacher training courses, in the development of supervised practicums, observe and imitate the teachers in the teaching profession. Imitation was understood as a necessary and possible condition to account for teacher training demand at that time.

Guided in this first understanding of practice, teacher training courses were used as strategies for the 
students - prospective teachers - to get ready for a good practice, the observation of good models, and their reproduction.

As to the first conceptualization of imitative practice, described by Pimenta (2005), one can establish a relationship with the model of teaching and training provided by Altet (1994) and, likewise, to the praxis of idea in the perspective of Vázquez (1977). When dealing with praxis, Vázquez distinguished it as the creative praxis and imitative or reiterative praxis. Here, one calls the attention to the imitative or reiterative praxis in order to realize the closeness between what Vázquez (1977) states, what Altet (1994) advocates, which is later asserted by Pimenta (2005).

The imitative or reiterative praxis, classified by Vázquez as inferior to the creative praxis, rejects the unpredictable and, therefore, remains unchanged, since, as stated by Vázquez (1977, p. 258), one already knows in advance, before the very accomplishment, which one can do and how to do, while in the creative praxis, one also creates a way of creating.

The imitative practice, both in the analysis made by Pimenta (2005) as in the classification made by Altet (1994) and the conceptualization by Vázquez (1977), is a practice that starts from a previous practice that at some point was created by someone. It is a practice that, although it may contribute in some way with the present, it does not transform it or modify it, since, as signaled by Vázquez, has no qualitative changes for the present.

The beginning of a change of a reiterative practice for a creative practice did not happen quickly and easily under the schooling in Brazil. Just resume the analysis done by Pimenta (2005), based on the historical perspective presented by this author, one sees the understanding that it was needed to overcome the reiterative practice bearing in mind the establishment of a creative practice was neither part of the theoretical-methodological framework nor by trainers or teachers who worked in teacher training courses. Thus, pedagogical practice, as part of the training of prospective teachers, was not understood as something important within the curricular organization of initial training courses for teachers.

In this sense, Pimenta (2005) pointed out that until the 1960s, the existence of a practicum as a requirement for the training of prospective teachers did not exist in the courses, because teaching was not considered as a profession itself but as a delegate mission mainly by women. Pimenta (2005) pointed out that the practice that was required from training teachers was merely one made possible by some subjects of the curriculum. Thus, as signaled by Pimenta (2005), it was up to the prospective teacher to reproduce through the imitation of teaching models considered effective to teach those children who had the requirements considered adequate for learning. This understanding of practice was prevalent in countries like Brazil until late 1970s and early 1980s.

Since the early 1980 s, different people began to realize that the notion of leading practice in hitherto teacher training courses caused a casualization of teaching and the teaching profession, and did not take into account the requirements of teachers' preparation for the educational reality of the moment.

Thus, from the 1980s, the discussion was marked in the relationship between the theoretical issues locked inside the teacher training courses and practical issues related to teaching in the exercise of the profession.

The emphasis about the notion of pedagogical practice, then falls to the idea that "Theory into practice is another thing", since, according to Pimenta (2005), the course does not ground theoretically the prospective teacher' performance, nor takes practice as a reference for the theoretical foundation, lacking thus theory and practice at the same time. The educational reality of primary school was not part of the discussions in teacher training courses, and there is a stage experience in the curricula of the courses. 


\section{Conclusion}

To reflect on the pedagogical practice in the context of teacher training courses, it is necessary to consider the relevance of a comprehensive theoretical and epistemological training ground on the foundations that support this practice. When performing this exploratory study on some conceptual guidance (Feiman-Neimser, 1990), models (Altet, 1994), and principles (Marcelo García, 1995) that support the pedagogical practice in the initial formation process of teachers, one cannot fail to consider that in some way, each of these guidelines, models, and principles is insufficient to account for the whole complexity of theory and pedagogical practice. Similarly, one has to refer to this training in the context of the pedagogical practice developed in the context of supervised practicums, highlighting even the practice is a time of great relevance of training in initial training and also in continuing education of teachers.

To conclude this article, it highlights the importance of studying the conceptual guidelines, models, and principles regarding teacher training. However, it called attention to the need for new strategies for effective initial and continuing teacher training. In addition, it is necessary to analyze the various reflections that have been proposed to promote a deeper understanding of teacher education both by basic education teachers, for degree students, student teachers, and the trainers of teacher education courses, too.

\section{References}

Altet, M. (1994). La formation profissionnalle des enseignants (The professional teacher training). Paris: Universitaires de France.

Altet, M. (2000). Análise das práticas dos professores e das situações pedagógicas (Analysis of the practices of teachers and pedagogical situations). Porto: Porto Press.

Feiman-Neimser, S. (1990). Teacher preparation: Structural and conceptual alternatives. In W. R. Houston, M. Haberman, \& J. Sikula (Eds.), Handbook of research on teacher education (pp. 212-233). New York, N.Y.: Macmillan.

Marcelo García, C. (1995). Formación del profesorado para el combio edutativo (Teacher training for educational change). Barcelona: Muntaner.

Mizukami, M. D. G. N. (1986). Ensino: As abordagens do processo (Education: The approaches of the process). São Paulo: EPU.

Pérez-Gómez, A. (1992). O pensamento prático do professor: A formação do professor como profissional reflexive (The practical thinking of the teacher: Teacher education as reflective practitioner). In N. Antonio (Ed.), Profissão professor (Teacher profession) (2nd ed.). Porto: Porto Press.

Pessoa, T. (2001). Aprender a pensar como professor: Contributo da metodologia de casos na formação da flexibilidade cognitive (Learning to think as a teacher: Contribuition of the case methodology in the formation of the cognitive flexibility) (Doctoral dissertation in Educational Sciences, Universidade de Coimbra).

Pimenta, S. G. (2005). O estágio na formação de professores: Unidade, teoria e prática (The stage in teacher education: Unity, theory and practice). São Paulo: Cortez.

Saviani, D. (1983). Escola e democracia (School and democracy). Campinas: Autores Associados.

Saviani, D. (1995). Pedagogia histórico-critica: Primeiras aproximações (Historical-critical pedagogy: First approaches) (5th ed.) Campinas: Autores Associados.

Simões, J. F. (1987). Quatro modelos ideais de formação de professores: O modelo empiricista, o modelo teoricista, o modelo compartimentado e o modelo integrado (Four ideal models of teacher training: The empiricist model). In Anais das Comunicações do Colóquio as Ciências da Educação e a Formação dos Professores (Annals of Scientific Communications Conference of the Educational Sciences and Teacher Education) (pp. 82-105). Lisboa: GEP/ME.

Vázquez, A. S. (1977). Filosofia da praxis (Philosophy of the praxis) (2nd ed.). Rio de Janeiro: Paz e Terra.

Zeichner, K. (1983). Alternative paradigms of teacher education. Journal of Teacher Education, 34(3), 3-9. 